\title{
Ionic radiocontrast inhibits endothelium-dependent vasodilation of the canine renal artery in vitro: possible mechanism of renal failure following contrast medium infusion
}

B. Discigil ${ }^{1}$,
P.R.B. Evora ${ }^{2}$,
P.J. Pearson ${ }^{3}$,
F. Viaro $^{2}$,
A.J. Rodrigues
and H.V. Schaff $^{3}$

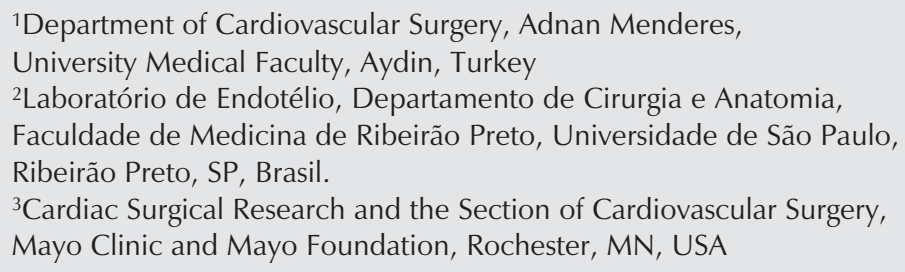

Correspondence

P.R.B. Evora

Rua Rui Barbosa, 367, Apto. 15

14015-120 Ribeirão Preto, SP

Brasil

Fax: +55-16-610-9890

E-mail: prbevora@keynet.com.br

Publication supported by FAPESP.

$\ldots \ldots \ldots \ldots \ldots \ldots$

Received March 17, 2003

Accepted October 2, 2003

\begin{abstract}
To determine if radiocontrast impairs vascular relaxation of the renal artery, segments (4-5 $\mathrm{mm}$ in length) of canine renal artery were suspended in vitro in organ chambers to measure isometric force $(95 \%$ $\mathrm{O}_{2} / 5 \% \mathrm{CO}_{2}$, at $\left.37^{\circ} \mathrm{C}\right)$. Arterial segments with and without endothelium were placed at the optimal point of their length-tension relation and incubated with $10 \mu \mathrm{M}$ indomethacin to prevent synthesis of endogenous prostanoids. The presence of nonionic radiocontrast (iohexol, Omnipaque 350, $1 \mathrm{ml}$ in $25 \mathrm{ml}$ control solution, 4\% (v/v)) did not alter endothelium-dependent relaxation to acetylcholine in rings precontracted with both norepinephrine and prostaglandin $\mathrm{F}_{2 \alpha}(\mathrm{N}=6)$. When the rings were precontracted with prostaglandin $\mathrm{F}_{2 \alpha}$, the presence of ionic contrast did not inhibit the relaxation of the arteries. However, in canine renal arteries contracted with norepinephrine, the presence of ionic radiocontrast (diatrizoate meglumine and diatrizoate sodium, MD-76, $1 \mathrm{ml}$ in $25 \mathrm{ml}$ control solution, 4\% (v/v)) inhibited relaxation in response to acetylcholine, sodium nitroprusside $(\mathrm{N}=6$ in each group), and isoproterenol $(\mathrm{N}=5 ; \mathrm{P}<0.05)$. Rings were relaxed less than $50 \%$ of norepinephrine contraction. Following removal of the contrast, vascular relaxation in response to the agonists returned to normal. These results indicate that ionic radiocontrast nonspecifically inhibits vasodilation (both cAMP-mediated and cGMP-mediated) of canine renal arteries contracted with norepinephrine. This reversible impairment of vasodilation could inhibit normal renal perfusion and act as a mechanism of renal failure following radiocontrast infusion. In the adopted experimental protocol the isoproterenol-induced relaxation of renal arteries precontracted with norepinephrine was more affected, suggesting a pivotal role of the cAMP system.
\end{abstract}

Key words - Radiocontrast

- Renal failure

- Nitric oxide

- Vasodilation 


\section{Introduction}

Nephrotoxicity due to the administration of radiocontrast material is a common cause of acute renal failure in hospitalized patients (1). The mechanism of contrast-mediated renal failure is not clear (2), although the coexistence of underlying renal disease or impairment of renal function appears to increase the incidence of renal failure following the administration of radiocontrast $(3,4)$.

Endothelial cells produce nitric oxide (NO) (5), which acts as an endogenous vasodilator and modulates vascular tone (6) and organ blood flow (7). If radiocontrast were to inhibit endothelium-dependent vasodilation, this could contribute to renal failure following radiological procedures. The purpose of the present study was to determine the effect of radiocontrast agents on endothelium-dependent and endothelium-independent vasodilation of the canine renal artery.

\section{Material and Methods}

\section{Animal preparation}

Heartworm-free mongrel dogs $(25-30 \mathrm{~kg})$ of either sex were anesthetized with pentobarbital sodium $(30 \mathrm{mg} / \mathrm{kg}$ intravenous injection; Fort Dodge Laboratories, Inc., Fort Dodge, IA, USA), and exsanguinated via the carotid arteries. The abdomen was opened, and the kidneys were harvested and immersed in cool oxygenated physiological salt solution of the following composition: 118.3 $\mathrm{mM} \mathrm{NaCl}, 4.7 \mathrm{mM} \mathrm{KCl}, 1.2 \mathrm{mM} \mathrm{MgSO}$, $1.22 \mathrm{mM} \mathrm{KH}_{2} \mathrm{PO}_{4}, 2.5 \mathrm{mM} \mathrm{CaCl}_{2}, 25.0 \mathrm{mM}$ $\mathrm{NaHCO}_{3}$, and $11.1 \mathrm{mM}$ glucose (control solution). The procedures and handling of the animals were reviewed and approved by the Institutional Animal Care and Use Committee of the Mayo Foundation.

\section{In vitro experiments}

The main renal artery and its branches were meticulously dissected free and placed in control solution. Segments $(4-5 \mathrm{~mm}$ in length) of blood vessel were prepared from the artery with special care taken not to touch the intimal surface of the vascular segments. In segments in which vascular smooth muscle function was to be tested without the influence of the endothelium, the endothelium was removed by gently rubbing the intimal surface of the blood vessel with a watchmaker forceps. This procedure removes the endothelium but does not affect the ability of vascular smooth muscle to contract or relax (8).

Vascular segments with and without endothelium were suspended in organ chambers $(25 \mathrm{ml})$ filled with control solution maintained at $37^{\circ} \mathrm{C}$ and bubbled with $95 \% \mathrm{O}_{2} / 5 \%$ $\mathrm{CO}_{2}, \mathrm{pH}$ 7.4. Each ring was suspended by two stainless steel clips passed through its lumen. One clip was anchored to the bottom of the organ chamber, and the other was connected to a strain gauge for measurement of isometric force (Statham UC 2, Gould, Cleveland, OH, USA). The rings were placed at the optimal point of their length-tension relation by progressively stretching them until contraction to $20 \mathrm{mM}$ potassium ions, at each level of distension, was maximal (9). In all experiments, the presence or absence of endothelium was confirmed by determining the response to $1 \mu \mathrm{M}$ acetylcholine in rings contracted with $20 \mathrm{mM}$ potassium ions $(5,10)$. After optimal tension was achieved, the renal artery rings were allowed to equilibrate in control solution for 30-45 min before administration of drugs.

\section{Protocols}

Segments of renal artery from the same animal were studied in a parallel eight-bath organ chamber system. Four pairs of renal artery segments were used in one of four protocols. To examine the effect of radiocontrast media on the vasorelaxation of renal artery constricted with $10 \mu \mathrm{M}$ norepi- 
nephrine, artery segments were studied in the presence of radiocontrast media $(1 \mathrm{ml}$ in $25 \mathrm{ml}$ control solution, $4 \%(\mathrm{v} / \mathrm{v}))$; ionic contrast was used in one protocol and nonionic contrast in the other. To study the reversibility of its effect, pairs of renal segments were exposed to ionic radiocontrast media of the same concentration for $60 \mathrm{~min}$ and then studied in control solution. To isolate the effect of the drug used for constricting the vessels, pairs of artery segments were constricted with $1 \mu \mathrm{M}$ prostaglandin $\mathrm{F}_{2 \alpha}\left(\mathrm{PgF}_{2 \alpha}\right)$ and studied in the presence of ionic radiocontrast; the potency of the dilators can be altered by the contractile agonist (11). Two pairs of renal artery segments were simply studied in control solution to serve as a control in each of these four protocols.

In all experiments, $1 \mu \mathrm{M}$ indomethacin was added to the organ chambers $40 \mathrm{~min}$ prior to the administration of drugs to prevent synthesis of endogenous prostanoids (8). Endothelium-derived relaxing factor is not a prostanoid, and its release is not inhibited by blockers of cyclooxygenase (5).

Three drugs were tested to study the radiocontrast effects on the renal artery vasodilatation: acetylcholine (endothelium-dependent cGMP-mediated vasodilatation), sodium nitroprusside (endothelium-independent cGMP-mediated vasodilatation) and isoproterenol (endothelium-independent cAMP-mediated vasodilatation).

\section{Drugs}

The following drugs were used: acetylcholine chloride, sodium nitroprusside, isoproterenol, $\mathrm{PgF}_{2 \alpha}$, norepinephrine, indomethacin and potassium chloride (all from Sigma, St. Louis, MO, USA). All drugs were prepared with distilled water except for indomethacin, which was dissolved in $10 \mu \mathrm{M} \mathrm{Na}_{2} \mathrm{CO}_{3}$. The concentrations are expressed as final molar concentration in the organ chambers. Diatrizoate meglumine and diatrizoate sodium (MD-76, $370 \mathrm{mgI} / \mathrm{ml}$, Mallinckrodt Medical,
Inc., St. Louis, MO, USA) were used as ionic radiocontrast media, and iohexol (Omnipaque 350, $350 \mathrm{mgI} / \mathrm{ml}$, Winthrop Pharmaceuticals, Division of Sterling Drug Inc., New York, NY, USA) was used as nonionic radiocontrast, $1 \mathrm{ml}$ in $25 \mathrm{ml}$ control solution ( $4 \%(\mathrm{v} / \mathrm{v})$ final concentration in the organ chamber). This $4 \%(\mathrm{v} / \mathrm{v})$ final concentration is close to the concentration of contrast during an examination.

\section{Statistical analysis}

Results are reported as mean $\pm \mathrm{SEM}$. In all experiments, $\mathrm{N}$ refers to the number of animals from which blood vessels were taken. In segments contracted with $\mathrm{PgF}_{2 \alpha}$ and norepinephrine, responses are reported as percent changes from the contracted levels. The negative logarithm of the effective molar concentration of agonist causing $50 \%$ inhibition ( $85 \%$ for isoproterenol) of the contraction to $\mathrm{PgF}_{2 \alpha}$ or norepinephrine $\left(\mathrm{IC}_{50}\right)$ was calculated for concentration-response curves, and the means of these values are presented. Data were analyzed statistically by analysis of variance (ANOVA) or by the Student $t$-test for either paired or unpaired observations. Differences were considered to be statistically significant when $\mathrm{P}$ was less than 0.05 .

\section{Results}

\section{Endothelium-dependent relaxation}

Acetylcholine. Acetylcholine ( $1 \mathrm{nM}$ to 100 $\mu \mathrm{M})$ induced comparable, concentration-dependent relaxation in control and in all experimental renal artery segments with endothelium (Figure 1A, B, C and D). Acetylcholine produced no significant change in tension in renal artery segments without endothelium.

The presence of nonionic radiocontrast medium did not impair the maximal relaxation or sensitivity to acetylcholine-induced relaxation in renal artery segments with endothelium precontracted with $10 \mu \mathrm{M}$ norepi- 
Figure 1. Endothelium-dependent relaxation in response to acetylcholine by the canine renal artery. Canine renal arteries were exposed to ionic or nonionic radiocontrast $(1 \mathrm{ml}$ per $25 \mathrm{ml}$ of Krebs solution) and contracted with norepinephrine or prostaglandin $F_{2 \alpha}$. When the contraction was stable, arteries were exposed to increasing concentrations of acetylcholine. A, Canine renal arteries exposed to nonionic radiocontrast and contracted with norepinephrine $(\mathrm{N}=$ 5). $B$, Canine renal arteries exposed to ionic radiocontrast and contracted with norepinephrine $(\mathrm{N}=6)$. $C$, Canine renal arteries exposed to ionic radiocontrast The radiocontrast was then washed out and the arteries were contracted with norepinephrine $(N=6)$. $D$, Canine renal arteries exposed to ionic radiocontrast and contracted with prostaglandin $\mathrm{F}_{2 \alpha}(\mathrm{N}=6)$. Data are reported as means \pm SEM. nephrine (Figure 1, N =5).

The presence of ionic radiocontrast medium impaired the maximal relaxation and sensitivity to acetylcholine-induced relaxation in renal artery segments with endothelium precontracted with $10 \mu \mathrm{M}$ norepinephrine (Figure $1 \mathrm{~B}, \mathrm{P}<0.05, \mathrm{~N}=6$ ). However,
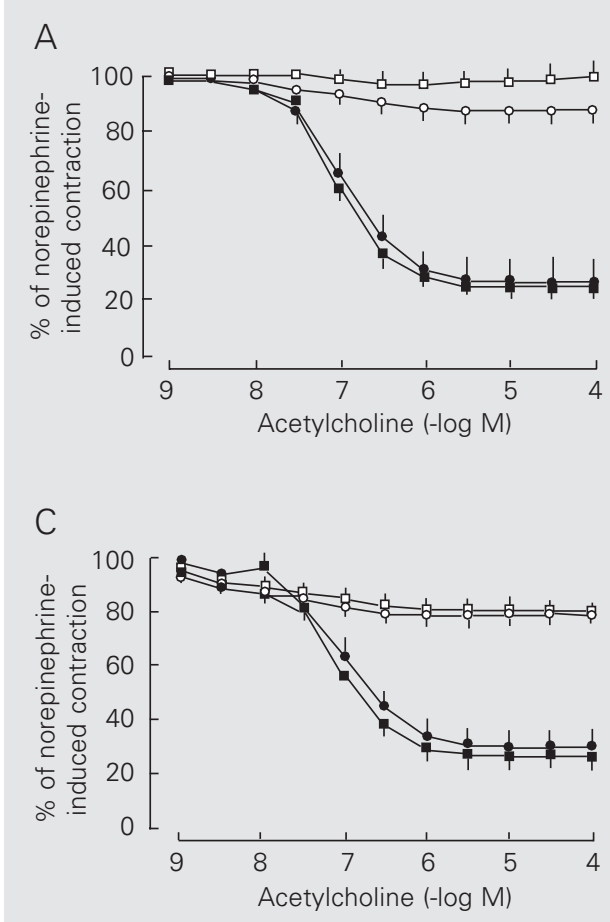

- Control with endothelium o Control without endothelium in the rings precontracted with $2 \mu \mathrm{MPgF} \mathrm{P}_{2 \alpha}$, the presence of ionic contrast did not impair the maximal relaxation or sensitivity to acetylcholine-induced relaxation (Figure 1C, N $=6$ ). Vascular relaxation to acetylcholine also returned to normal following removal of the contrast (Table 1).
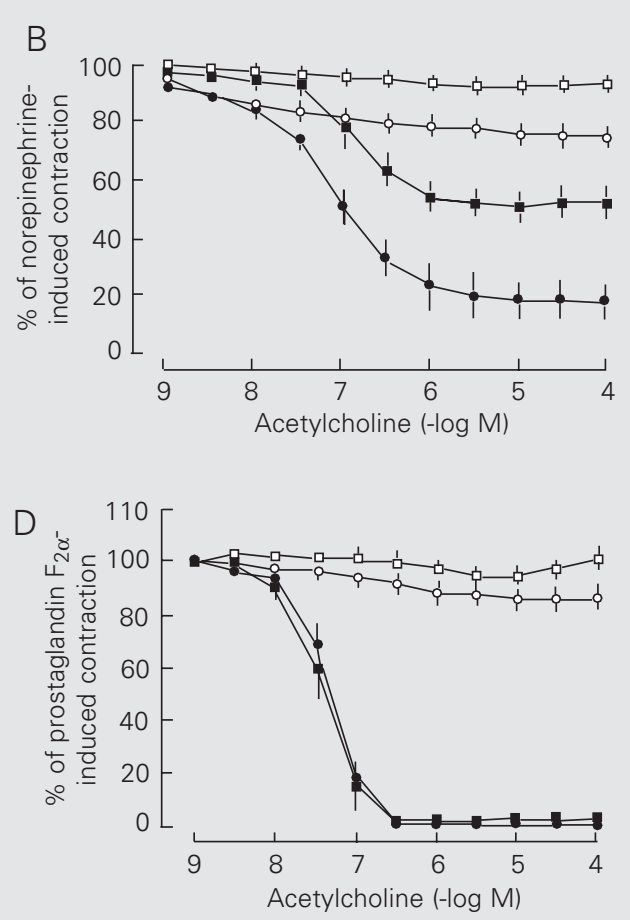

Radiocontrast with endothelium

$\square$ Radiocontrast without endothelium

Table 1. Inhibition $(-\log M)$ of control and treated renal artery segments with and without endothelium.

\begin{tabular}{|c|c|c|c|c|c|c|c|}
\hline & \multicolumn{5}{|c|}{ Ionic radiocontrast } & \multirow{2}{*}{\multicolumn{2}{|c|}{$\begin{array}{c}\text { Nonionic radiocontrast } \\
\begin{array}{c}\text { Norepinephrine } \\
\text { contraction }\end{array}\end{array}$}} \\
\hline & \multicolumn{3}{|c|}{$\begin{array}{l}\text { \% Norepinephrine } \\
\text { contraction }\end{array}$} & \multicolumn{2}{|c|}{$\begin{array}{l}\% \text { Prostaglandin } \\
\mathrm{F}_{2 \alpha} \text { contraction }\end{array}$} & & \\
\hline & Control & $\begin{array}{l}\text { In the } \\
\text { presence }\end{array}$ & $\begin{array}{c}\text { After } \\
\text { exposure }\end{array}$ & Control & $\begin{array}{l}\text { In the } \\
\text { presence }\end{array}$ & Control & $\begin{array}{c}\text { In the } \\
\text { presence }\end{array}$ \\
\hline $\begin{array}{l}\text { With endothelium } \\
\text { Acetylcholine (50) }\end{array}$ & $6.89 \pm 0.18$ & + & $6.80 \pm 0.09$ & $7.34 \pm 0.08$ & $7.41 \pm 0.13$ & $6.64 \pm 0.21$ & $6.81 \pm 0.07$ \\
\hline Without endothelium & & & & & & & \\
\hline Sodium nitroprusside (50) & $6.83 \pm 0.08$ & $6.21 \pm 0.24^{*}$ & $7.12 \pm 0.23^{*}$ & $7.58 \pm 0.06$ & $7.63 \pm 0.08$ & & \\
\hline Isoproterenol (85) & $7.73 \pm 0.09$ & $5.52 \pm 0.55^{*}$ & $6.71 \pm 0.34 *$ & $7.34 \pm 0.13$ & $7.23 \pm 0.17$ & & \\
\hline
\end{tabular}

+Rings were relaxed less than $50 \%$ of norepinephrine contraction. The numbers in parentheses indicate effective dose (ED) values. ${ }^{*} P<0.05$ compared to control (ANOVA). 


\section{Endothelium-independent relaxation}

Cyclic AMP-mediated relaxation. Isoproterenol ( $1 \mathrm{nM}$ to $100 \mu \mathrm{M})$ induced comparable concentration-dependent relaxation in control and experimental renal artery segments without endothelium (Figure 2A,B). The presence of ionic radiocontrast medium altered the maximal relaxation induced by isoproterenol and changed the sensitivity of the vascular smooth muscle to the compound in the rings precontracted with $10 \mu \mathrm{M}$ norepinephrine (Figure 2A; $\mathrm{P}<0.05, \mathrm{~N}=6$ ), but did not affect the relaxation in the rings precontracted with $2 \mu \mathrm{M} \mathrm{PgF}_{2 \alpha}$ (Figure $2 \mathrm{~B}$, $\mathrm{N}=6$ ). In addition, removal of the ionic radiocontrast restored, but still impaired, the relaxation sensitivity of the smooth muscle to isoproterenol $(\mathrm{P}<0.05, \mathrm{~N}=6$; Table 1$)$.

Cyclic GMP-mediated relaxation. Sodium nitroprusside ( $1 \mathrm{nM}$ to $100 \mu \mathrm{M})$ induced comparable concentration-dependent relaxation in control and experimental renal artery segments without endothelium (Figure $3 \mathrm{~A}, \mathrm{~B})$. The presence of ionic radiocontrast medium impaired the maximal relaxation and sensitivity to sodium nitroprusside-induced relaxation in renal artery seg-

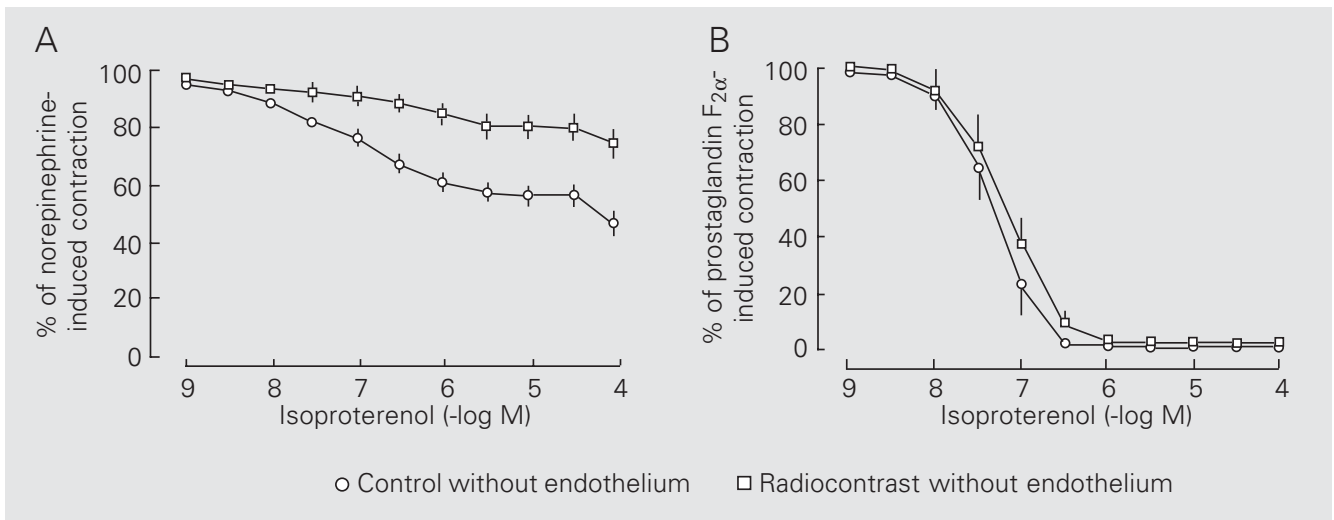

Figure 2. Relaxation in response to isoproterenol by the canine renal artery. Canine renal arteries were exposed to ionic radiocontrast $\left(1 \mathrm{ml}\right.$ per $25 \mathrm{ml}$ of Krebs solution) and contracted with norepinephrine or prostaglandin $\mathrm{F}_{2 \alpha}$. When the contraction was stable, arteries were exposed to increasing concentrations of isoproterenol. $A$, Canine renal arteries exposed to ionic radiocontrast and contracted with norepinephrine. $(N=6)$; $B$, Canine renal arteries exposed to ionic radiocontrast and contracted with prostaglandin $F_{2 \alpha}(N=6)$. Data are reported as means \pm SEM.

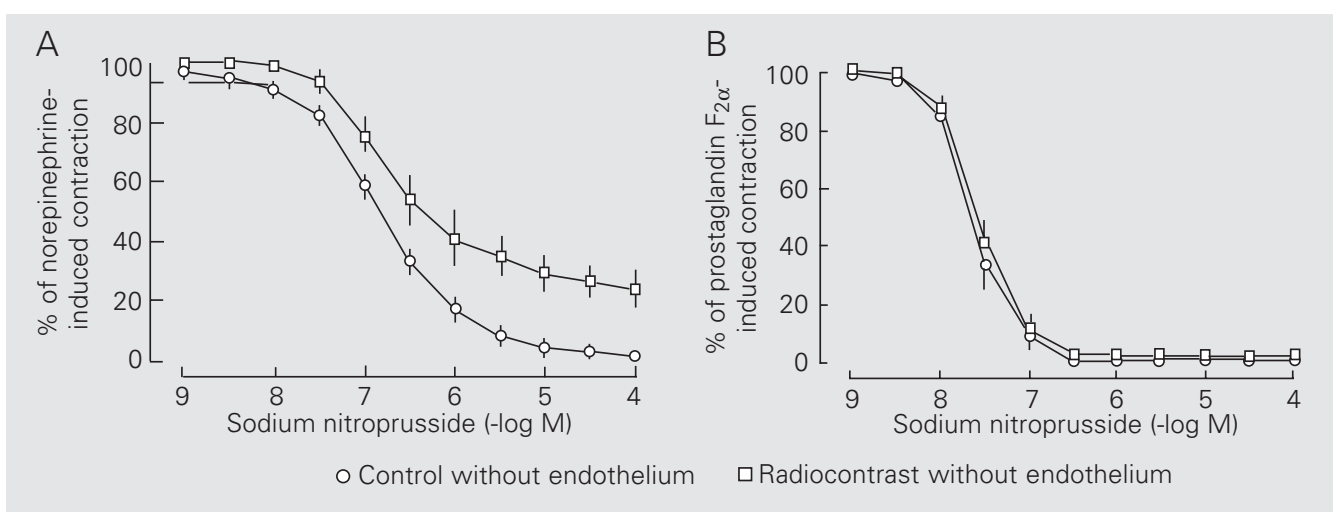

Figure 3. Relaxation in response to sodium nitroprusside by the canine renal artery. Canine renal arteries were exposed to ionic radiocontrast ( $1 \mathrm{ml}$ per $25 \mathrm{ml}$ of Krebs solution) and contracted with norepinephrine or prostaglandin $F_{2 \alpha}$. When the norepinephrine contraction was stable, arteries were exposed to increasing concentrations of sodium nitroprusside. A, Canine renal arteries exposed to ionic radiocontrast and contracted with norepinephrine $(\mathrm{N}=6)$. $B$, Canine renal arteries exposed to ionic radiocontrast and contracted with prostaglandin $\mathrm{F}_{2 \alpha}$. Data are reported as means \pm SEM. 
ments contracted with $10 \mu \mathrm{M}$ norepinephrine $(\mathrm{P}<0.05, \mathrm{~N}=6$; Figure $3 \mathrm{~A})$. However, in renal artery segments without endothelium precontracted with $2 \mu \mathrm{MPgF}_{2 \alpha}$, its presence did not impair maximal relaxation or sensitivity to the compound (Figure 3B, N = 6). One-hour exposure of renal artery segments to $4 \%(\mathrm{v} / \mathrm{v})$ concentration of ionic radiocontrast enhanced the sodium nitroprusside-induced relaxation of smooth muscle $(\mathrm{P}<0.05, \mathrm{~N}=6$; Table 1).

\section{Vascular smooth muscle contraction}

Norepinephrine. Norepinephrine $(10 \mu \mathrm{M})$ caused contraction of renal artery rings with endothelium (13.52 $\pm 1.83 \mathrm{~g}, \mathrm{~N}=6)$. The presence of ionic or nonionic radiocontrast did not affect the contraction of renal artery segments with endothelium to $10 \mu \mathrm{M}$ norepinephrine, $17.07 \pm 3.36$ vs $14.96 \pm 0.57 \mathrm{~g}$, respectively.

Prostaglandin $F_{2 \alpha} \cdot \operatorname{PgF}_{2 \alpha}(2 \mu \mathrm{M})$ caused lesser contraction in renal artery segments with endothelium in the presence of ionic radiocontrast compared to control rings, 5.57 \pm 1.06 vs $8.63 \pm 1.48 \mathrm{~g}$, respectively.

\section{Discussion}

It has been shown that contrast media have deleterious effects, both structural and functional, on the endothelium $(12,13)$. Hyperosmolarity $(4,14)$ and the contrast medium itself (15) account for most of the cell toxicity. Radiocontrast is also a well-documented renal vasoconstrictor (16). Even small residual amounts of intravascular contrast medium left after a preoperative roentgen examination at the time of operation may increase the risk of renal failure, which is a serious complication after aortoiliac surgery (17).

The renal endothelium synthesizes NO, which promotes vasodilation (18-20) in the blood vessel. The main renal artery plays a major regulatory role in renal blood flow and vascular resistance. Intraluminally released NO in the main renal artery could travel downstream to the microcirculatory bed to promote vasodilation and to determine organ blood flow and transcapillary fluid transfer $(18,19)$.

The pathophysiologic role of NO in contrast medium nephrotoxicity is a matter of controversy. The administration of radiocontrast material resulted in a significant decrease in urinary guanosine 3 ',5'-cyclic monophosphate as well as $\mathrm{NO}_{2}+\mathrm{NO}_{3}$ excretion. This decrease was significantly attenuated by L-arginine, suggesting that NO plays a major role in the pathogenesis of radiocontrast-induced acute renal failure (21). One recent study suggested that contrast media increase vascular endothelial permeability by inhibiting NO production, with consequent vascular endothelium-related adverse effects (22).

The present study was carried out to demonstrate and characterize the effect of radiocontrast media on the ability of the renal artery to relax. The major findings were: 1 ) non-ionic radiocontrast does not inhibit endothelium-dependent or endothelium-independent vasodilation of the canine renal artery; 2) ionic radiocontrast nonspecifically inhibits vasodilation (both endothelium-dependent and endothelium-independent, cGMP or cAMP-mediated) of canine renal arteries contracted with norepinephrine; 3 ) the inhibitory effect of ionic radiocontrast occurs specifically on renal arteries contracted with norepinephrine, because renal arteries exposed to ionic radiocontrast but contracted with $\mathrm{PgF}_{2 \alpha}$ exhibit normal vasodilation.

Combined acute inhibition of the synthesis of NO with L-nitroarginine methyl ester (L-NAME) and of prostacyclin synthesis with indomethacin predisposes rats to severe renal injury from radiographic contrast media (23). The marked impairment of relaxation of renal vessels contracted with norepinephrine observed in the present study suggests a 
pivotal role of the cyclic AMP system in addition to the cyclic GMP-mediated signaling mechanisms.

Also, it was suggested that the vasodilatory response of the vasculature to contrast agents is directly related to osmolality and is not mediated by NO (24). In the present study, the inhibition of vasorelaxation was not due to hyperosmolarity per se because relaxation was normal when $\mathrm{PgF}_{2 \alpha}$ was used as the contracting agent. Also, it was not due to a toxic effect because the inhibitory action of ionic radiocontrast is reversible; washout of radiocontrast restores endothelium-dependent and -independent relaxation of previously treated renal arteries.

\section{References}

1. Hou SH, Bushinsky DA, Wish JB, Cohen JJ \& Harrington JT (1983). Hospital-acquired renal insufficiency: a prospective study. American Journal of Medicine, 74: 243-248.

2. Morsing P, Persson AEG \& Roberg U (1988). A microcomputer assessment of the effects of contrast media of different osmolality. Investigative Radiology, 23: 767-771.

3. Heyman SN, Brezis M, Rubinoff ZG, Lechene C, Epstein FH \& Rosen $S$ (1988). Acute renal failure with selective medullary injury in the rat. Journal of Clinical Investigation, 82: 401-412.

4. Katzberg RW (1988). Renal effects of contrast media. Investigative Radiology, 23 (Suppl 1): 157-160.

5. Furchgott RF \& Zawadzski JV (1980). The obligatory role of endothelial cells in the relaxation of arterial smooth muscle by acetylcholine. Nature, 299: 373-376.

6. Ignarro LJ (1989). Endothelium-derived nitric oxide: actions and properties. FASEB Journal, 3: 31-36.

7. Brezis M, Heyman SN, Dinour D, Epstein FH \& Rosen S (1991). Role of nitric oxide in renal medullary oxygenation. Journal of Clinical Investigation, 88: 390-395.

8. Pearson PJ, Schaff HV \& Vanhoutte PM (1990). Acute impairment of endothelium-dependent relaxations to aggregating platelets following reperfusion injury in canine coronary arteries. Circulation Research, 67: 385-393

9. Cohen RA, Shepherd JT \& Vanhoutte PM (1983). 5-Hydroxytryptamine can mediate endothelium-dependent relaxation of coronary arteries. American Journal of Physiology, 245: H1077-H1078.

10. DeMey JG \& Vanhoutte PM (1983). Anoxia and endothelium-dependent reactivity of the canine femoral artery. Journal of Physiology, 335: 65-74.

11. Miller VM \& Vanhoutte PM (1990). Relaxations to SIN-1, nitric oxide, and sodium nitroprusside in canine arteries and veins. Journal of Cardiovascular Pharmacology, 14 (Suppl 11): 67-71.

12. Schneider KM, Ham KN, Friedhuber A \& Rand MJ (1988). Functional and morphological effects of ioxilan, iohexol, and diatrizoate on endothelial cells. Investigative Radiology, 23 (Suppl 1): S147-S149.

13. Bettmann M (1988). Ionic versus nonionic contrast agents and their effects on blood components. Clinical summary and conclusions. Investigative Radiology, 23 (Suppl 2): S378-S380.
14. Schneider KM \& Rand MJ (1988). Vasodilation and vasoconstriction in the rabbit isolated aorta. Effects of ioxilan, iohexol, and diatrizoate. Investigative Radiology, 23 (Suppl 1): S150-S152.

15. Laerum $F$ (1983). Acute damage to human endothelial cells by brief exposure to contrast media in vitro. Radiology, 147: 681-684.

16. Katzberg WR, Schulman G, Meggs LD, Caldicott WJH, Damiano MM \& Hollenberg NK (1983). Mechanism of renal response to contrast medium in dogs. Decrease in renal function due to hypertonicity. Investigative Radiology, 18: 74-80.

17. Almen T, Bergqvist D, Cederholm C, Golman K, Husberg B, Takolander R \& Weibull H (1988). Interactive effects on renal function between renal ischemia and intravascular contrast media. Investigative Radiology, 23 (Suppl 1): S161-S163.

18. Kon V, Harris RC \& Ichikawa I (1990). A regulatory role for large vessels in organ circulation. Endothelial cells of the main renal artery modulate intrarenal hemodynamics in the rat. Journal of Clinical Investigation, 85: 1728-1733.

19. Pawloski JR \& Chapnick BM (1990). Release of EDRF from canine renal artery by leukotriene D4. American Journal of Physiology, 258 (Part 2): PH1449-PH1456.

20. Toda N, Bian K, Akiba T \& Okamura $T$ (1987). Heterogeneity in mechanisms of bradykinin action in canine isolated blood vessels. European Journal of Pharmacology, 135: 321-329.

21. Schwartz D, Blum M, Peer G, Wollman Y, Maree A, Serban I, Grosskopf I, Cabili S, Levo Y \& laina A (1994). Role of nitric oxide (EDRF) in radiocontrast acute renal failure in rats. American Journal of Physiology, 267 (Part 2): F374-F379.

22. Furuta W, Yamauchi A, Dohgu S, Nakagawa S, Sendo T, Makino K, Oishi R \& Kataoka Y (2002). Contrast media increase vascular endothelial permeability by inhibiting nitric-oxide production. Investigative Radiology, 37: 13-19.

23. Wang YX, Jia YF, Chen KM \& Morcos SK (2001). Radiographic contrast media induced nephropathy: experimental observations and the protective effect of calcium channel blockers. British Journal of Radiology, 74: 1103-1108.

24. Baile EM, Pare PD, D'yachkova Y \& Carere RG (1999). Effect of contrast media on coronary vascular resistance: contrast-induced coronary vasodilation. Chest, 116: 1039-1045. 